\title{
Reembalagem: projeto gráfico e educação estética
}

\section{Repacking: graphic design and aesthetic education}

\section{Reempaque: diseño gráfico y educación estética}

\author{
iD (9) Juliana Garcia de Mendonça Hanke \\ Universidade Estadual de Maringá (UEM), Maringá, Paraná, Brasil. \\ E-mail: juhhanke@hotmail.com \\ iD (9) Alice Áurea Penteado Martha \\ Universidade Estadual de Maringá (UEM), Maringá, Paraná, Brasil. \\ E-mail: apmartha@uol.com.br
}

Resumo: As obras machadianas, ao longo do tempo, têm sido reembaladas, com vistas à sua manutenção, circulação e consumo. Ávido por ampliação de público, o mercado editorial investe intensamente nessa produção, visando, inclusive, à sua destinação a crianças e jovens. A partir desse prisma, neste texto levantamos, analisamos e categorizamos o material gráfico de obras do escritor, publicadas por diferentes editoras, cujos textos, integrais, passam pelo processo de reembalagem, na acepção empregada pela pesquisadora Sandra Beckett.

Palavras-chave: Contos machadianos. Projeto gráfico-editorial. Educação estética.

Abstract: The works of Machado, over time, have been repacked with a view to its maintenance, circulation and consumption. Avid for audience expansion, the publishing market invests heavily in this production, even aiming at its destination for children and young people. From this point, in this text, we survey, analyze and categorize the graphic material of the 
writer's works, published by different publishers, whose texts, in full, go through the repackaging process, as used by researcher Sandra Beckett.

Keywords:. Works of Machado de Assis. Graphic-editorial project. Aesthetic education.

Resumen: Las obras de Machado, a lo largo del tiempo, han sido reempaquetadas, con pretención a su mantenimiento, circulación y consumo. Ávido de ampliar el público, el mercado editorial invierte fuertemente en esta producción, apuntando, al mismo tiempo, a que su destino sea infantil y juvenil. Desde este punto de vista, en este texto recogemos, analizamos y categorizamos el material gráfico de las obras del escritor, editadas por diferentes editoriales, cuyos textos, en su totalidad, pasan por el proceso de reempaquetado, en el sentido utilizado por la investigadora Sandra Beckett.

Palabras clave: Cuentos de Machado de Assis. Proyecto gráfico-editorial. Educación estética.

Submetido em 29 de setembro de 2020.

Aceito em 27 de novembro de 2020.

Publicado em 21 de julho de 2021. 


\section{Introdução}

Na década de 1970, época em que se consolida a chamada indústria cultural, emerge uma maneira de produção, circulação e consumo de obras de arte, a denominada cultura de massa, cuja reprodutibilidade facilita o acesso do cidadão comum aos bens culturais, antes consumidos, quase que exclusivamente, por eruditos.

Uma prática anterior ao estabelecimento dessa indústria perpetra-se. De acordo com Bourdieu (2015), as instituições de ensino - que deveriam (e devem) exercer parte do papel de levar seus estudantes ao contato com a arte e à apreensão dos bens culturais - desempenham a função de alargar ainda mais a distância entre os alunos e a fruição da cultura erudita. Isso porque tal instituição requer de seus alunos a posse de conhecimentos linguístico e cultural para a assimilação do capital cultural, mas não lhes fornece tais competências.

Advinda da sociedade industrializada, a indústria da cultura de massa foi foco de muitos embates teóricos: há aqueles que afirmam ser ela o motivo do enfraquecimento da arte erudita - como Adorno (2002), que a considera um grande mal à cultura - e há os que a enxergam como uma possibilidade de acesso aos bens cultuais. De qualquer maneira, em pleno século XXI, o movimento intensifica-se, a cultura de massa ganha cada vez mais espaço e merece ser estudada.

Com o estabelecimento da indústria cultural, houve crescimento do mercado editorial, que não ficaria atrás em sua busca por (dentre outros aspectos) lucro. Na intenção de atender ao novo público, ávido por consumir e carente por bens culturais, as editoras realizam investimento em projetos gráfico-editoriais para colocar em circulação as mais variadas obras literárias, desde produções contemporâneas até as que pertencem ao denominado cânone. No que se refere às últimas, a adequação aos padrões de consumo vigentes se configura, além da valorização do aspecto 
material do livro, pela preservação integral do texto do autor. Nesse caso, como observa Chartier, o investimento material orienta, em certa medida, a leitura do texto literário, haja vista que em uma obra existem códigos (protocolos de leitura) inseridos pelo próprio escritor e outros pelo trabalho de editoração (CHARTIER, 1994).

Como o sistema da indústria cultural é regido, basicamente, pelos imperativos da concorrência que busca conquistar mercado, e a estrutura do seu produto advém de condições econômicas e sociais de sua produção, compreendemos, como Bourdieu (2015), que o grande enfoque dessa produção é a rentabilidade dos investimentos e a maior extensão possível do público. Dessa forma, o destino de um texto é afetado por uma série de aspectos resultantes da "relação entre a posição do autor no campo de produção [...] e a produção do editor no sistema de produção e circulação" (BOURDIEU, 2015, p. 162).

Ao constatarmos que a revolução cultural (iniciada por volta de 1970) revelou os jovens como camada social atuante e consumidora, conquistando direitos e espaço na sociedade, observamos um aumento de insumos destinados a eles, que passaram a ser vistos, então, como um grupo com grande poder de compra (HOBSBAWM, 1995, p. 317). E é nesse público que o mercado do livro encontra um nicho rentável, o que motiva e desencadeia a busca de produções que cativem jovens leitores.

Para fundamentar a discussão proposta nesta abordagem da produção de Machado de Assis, escolhemos textos machadianos que se mantêm integrais e que sofreram apenas alterações nos aspectos materiais que compõem seus projetos gráficos. Como em 2008, em razão da efeméride relativa aos cem anos da morte do escritor, o mercado editorial realizou inúmeros projetos muitas vezes ousados, criativos e diferenciados para homenageá-lo, questionamo-nos que tipo de obras ele preparou para a narrativa de Machado de Assis, observando, principalmente, se tratando do objeto livro, quais as alterações materiais nele operadas, que artifícios foram empregados para ampliar o público leitor visando à manutenção, circulação e consumo das obras desse autor. 
Além de ser um autor clássico, do cânone brasileiro, cuja leitura é muitas vezes exigida em ambientes escolares, seus textos encontram-se em domínio público, o que permite às editoras a edição sem qualquer autorização ou pagamento de direitos autorais. Como são inúmeras e diversificadas as obras preparadas pelo mercado, selecionamos três livros publicados por diferentes editoras - Conto de escola, publicado em 2002 pela editora Cosac Naify; A Agulha e a Linha: Um apólogo, publicado em 2008 pela editora Ao Livro Técnico; Uns braços, edição de 2012 lançada pela editora SESI-SP editora -, com a intenção de revelar como o mercado do livro prepara os textos do escritor e como tal trabalho pode influenciar na educação estética do leitor.

Diante desse objetivo, traçamos um percurso que se inicia com o trabalho gráfico e editorial, envolvendo tipografia, diagramação, ilustrações e paratextos. Com base nas concepções de Chartier (1994) e Cademartori (2008), discutimos a influência desses elementos no processo de leitura. Se os leitores contemporâneos de Machado de Assis, para Hélio Seixas Guimarães (2014, p. 12), eram "os críticos mais bem preparados do país", um público oitocentista, formado por intelectuais da época, devemos pressupor que, por propiciar reflexões a respeito da natureza humana, a obra machadiana não se restringe apenas ao século XIX; ao contrário, a atemporalidade de seus escritos permite que sejam lidos e apreciados nos dias atuais, como nos ensina Todorov (2009), ao afirmar que a verdadeira arte é sim estética e fruição, mas também se relaciona com o mundo, dialoga com a realidade, o que pode explicar a circulação de Machado entre públicos tão distintos. O mercado editorial facilita essa circulação, aproximando, por meios materiais, a obra machadiana de seu novo público. Esse cruzamento de fronteiras da ficção é chamado, por Beckett, de fenômeno crossover fiction (BECKETT, 2009), aspecto também abordado neste texto, que, expondo de maneira concisa, trata-se de um fenômeno em que a ficção rompe a barreira que tradicionalmente separa o público infantil do adulto - um texto escrito para crianças que é apropriado por adultos; obras escritas para um público adulto que são lidas por crianças e jovens. 


\section{Reembalagem: Trabalho gráfico e educação estética}

Como o corpus selecionado para o presente artigo abarca obras de um autor cujos textos estão em domínio público, nenhuma editora ou agente do mercado livreiro detém os direitos autorais de tais escritos. Sendo assim, a concorrência na venda por determinados livros pode tornar-se mais acirrada, são inúmeras as edições dos textos canônicos e as diferentes editoras buscam ser criativas em suas "reembalagens". Nas estantes de uma livraria (e, às vezes, até de um supermercado ou banca de revistas) temos oportunidade de escolher entre dezenas de opções de um mesmo texto.

O termo "reembalagem", usado por Beckett (2009), designa o investimento na materialidade do livro, reedições lançadas pelo mercado. Lembremos que "[...] não há texto fora do suporte que o dá a ler (ou a ouvir), e sublinhar o fato de que não existe a compreensão de um texto, qualquer que ele seja, que não depende das formas através das quais ele atinge o seu leitor" (CHARTIER, 1994, p.17). Sendo o texto o trabalho do autor e o objeto-livro o trabaIho do editor, podemos considerar a existência de protocolos de leitura colocados por ambos (CHARTIER, 1994), respaldando, pois, a ideia de que a materialidade da obra influencia a leitura. Não apenas isso, mas a reembalagem permite que um texto chegue a um público diferente ao destinado a princípio, tendo, portanto, um papel significativo no cruzamento das barreiras da ficção que separam o público adulto do infantil e do juvenil - fenômeno crossover fiction (BECKETT, 2009).

Reembalar, portanto, envolve o processo de reeditar, reinventar o projeto gráfico, inserir paratextos, repensar a editoração. Um mesmo livro pode ser investido de características editoriais que atraiam ambos os públicos, acompanhando os gostos de cada época para não sair de circulação e alcançar um maior número de leitores. Pode ser que o editor decida publicar um livro para um público distinto do pretendido pelo autor (BECKETT, 2009). Todo 
esse movimento é possibilitado pela materialidade, mas aspectos como períodos temporais e culturais também influenciam nas escolhas do mercado do livro.

A capa, por exemplo, é trabalhada na reembalagem de um livro e pode ser um instrumento de grande contribuição para a catalogação, pois nela pode constar a indicação da faixa etária do público pretendido. A capa é um dos primeiros contatos que o leitor tem com o livro, além de sua função primária - a proteção do miolo - e de despertar o interesse do leitor, precisa condizer com o seu conteúdo (ALMEIDA, 2015). A introdução, o prefácio e o posfácio, as notas, os glossários e as imagens são componentes gráfico-editoriais que apresentam sugestões de quais leitores a obra pretende alcançar (BECKETT, 2009).

A influência do trabalho gráfico sobre a leitura e, consequentemente, a sua importância no processo de assimilação do conteúdo também precisa ser enfatizada. Ao compreendermos como um paratexto e como a diagramação podem orientar tal processo, entendemos que a educação estética caminha lado a lado do trabalho editorial. Um projeto gráfico bem elaborado pode incentivar à leitura e aguçar o senso estético do leitor; ao passo que uma má elaboração pode desanimar o leitor levando-o a desistir da leitura. A estudiosa Almeida (2015, p. 63) afirma que esse também pode ser um diferencial na escolha pelo livro de uma editora e não pelo da outra, "principalmente nos casos em que a obra já está em domínio público, possuindo, assim, inúmeras edições diferentes".

Chartier (1994), valorizando aspectos materiais do livro, afirma que a ordem do discurso fica mais legível em decorrência da aeração da página por meio do aumento do número de parágrafos, o que rompe a sequência ininterrupta do texto e das linhas subdivididas. Sendo assim, os editores propõem uma nova leitura dos mesmos textos ou dos mesmos gêneros - "uma leitura que fragmenta os textos em unidades separadas, e que reencontra, na articulação visual da página, as conexões intelectuais ou discursivas do raciocínio" (CHARTIER, 1994, p. 19). Por sua vez, Cademartori (2008) considera que a materialidade do livro pode ritmar a leitura 
e viabilizar a assimilação das significações contidas no texto, tendo em vista que o projeto gráfico tanto torna a obra mais fluída como mais truncada. De acordo com a pesquisadora, a diagramação permite "uma leitura mais confortável, com capas que atraiam a atenção dos prováveis leitores" (CADEMARTORI, 2008, p. 92).

A tipografia confere legibilidade ao texto, a disposição da mancha gráfica é como uma "comunicação por imagens", chamada de "enunciação gráfica" (RAMOS, 2011, p. 145); em outros termos, todas as imagens do livro - não apenas as ilustrações, mas a própria mancha textual, a diagramação e os demais paratextos - comunicam intenções e sentidos. Ainda sob esse aspecto, para Graça Ramos (2011), a valoração das imagens não se relaciona com a quantidade apresentada em um livro, pelo contrário, o valor de uma ilustração está diretamente ligado ao papel por ela desempenhado na narrativa e, sendo assim, os detalhes têm grande importância.

As funções são as mais variadas, desde a reiteração do texto escrito até a sua contradição, sendo possível também desempenhar papéis de ampliação das significações ou sugestões do enredo, "[a]s imagens podem concordar, tencionar, negar, expandir ou propor uma visualidade nova para o que está dito com palavras" (RAMOS, 2011, p. 146). Linhas, cores e formas conferem ritmo visual à ilustração, e, quanto mais ritmo, maior e mais rica é a contribuição para a estruturação da narrativa, tornando a obra mais ou menos cansativa e/ou clara. Assim, frente a várias edições de um mesmo texto, devemos optar por obras com um projeto gráfico que contribua para a fluidez da leitura e para ampliar as possibilidades de sentido, que aproximam e atraem o jovem leitor para o texto, ampliando também seus horizontes.

Diante disso, partimos do pressuposto de que as diversas expressões de arte usadas na composição de uma obra podem proporcionar ao leitor uma educação estética. Tal educação diz respeito à ampliação do conhecimento daquele que lê, desenvolvendo sua sensibilidade e criticidade no que se refere a manifestações artísticas e culturais variadas, à percepção acerca da composição 
daquela obra, aprimorando a sua capacidade de atribuir significados e realizar inferências que extrapolam o texto escrito. No caso dos livros aqui analisados, as ilustrações têm importante papel de auxiliar para a compreensão do narrado, mas a integralidade do texto não será prejudicada se elas estiverem ausentes. Em situações como essa, o texto imagético subordina-se ao verbal.

Apesar de a totalidade do texto, nesse caso, não ser prejudicada pela ausência das imagens, vivemos em uma época de cada vez menos linearidade, numa sociedade cada vez mais visual, o que nos leva a admitir que a maneira como, em especial, os jovens e as crianças se apropriam dos livros mudou. Camargo (2003) afirma que tal público tem preferência por obras que apresentem ilustrações - e acrescentamos, um projeto gráfico atrativo e que desperte de alguma maneira no leitor um sentimento por aquela obra - e garante que, ao longo do tempo, imagens são parte essencial dos endereçados a esse público, tendo elas não a função de traduzir um texto, mas de acompanhá-lo.

Sandroni (2013) vai além ao afirmar que não podemos designar a esse paratexto apenas a função de estar junto ao texto, podendo ocupar uma posição de importância quando não se resume a "um processo narrativo, mas também um modo de influência, fazer a cabeça, principalmente quando se trata de uma população menos letrada (SANDRONI, 2013, p. 14 - grifo da autora). Para Graça Ramos (2011), uma ilustração pode ter tido tanta influência na vida do leitor, a ponto de interferir na forma como lida com as alegrias, medos e anseios decorrentes da infância e juventude. Não apenas isso, mas representam símbolos e signos que enriquecem o mundo infantil e oferecem sustentação à vida adulta, tendo em vista a necessidade que todos temos de simbolizar o real para que possamos nos constituir, isso porque as ilustrações são concernentes à esfera do simbólico, sendo mediadoras entre o leitor e a realidade (RAMOS, 2011, p. 16-17).

Terry Eagleton (2001, p. 226), embasado na psicanálise lacaniana, discute o "imaginário" infantil aludindo ao estado do sujeito que atribui a definição do "eu" aos objetos, e dos objetos ao "eu", 
de maneira cíclica e infinda. Tais ideias contribuem para nossos estudos e nos permitem compreender a importância do simbolizar porque, com o crescimento, a criança permanece com essa atitude de identificação e se constrói. A ausência do objeto real permite sua significação por meio dos signos, por isso simbolizar a realidade torna-se uma maneira de lidar com verdades como a morte. Independente de tais signos serem imagens ou palavras, seu papel é de representação do real ausente, sendo expressões ou reflexões da realidade e permitindo a organização da experiência humana e a tradução das estruturas mentais do indivíduo (EAGLETON, 2001, p. 250).

Cademartori (2008) afirma que a grande produção de livros destinados ao público infantil e juvenil leva os ilustradores a se encontrarem em meio à situação de "concorrência". A qualidade de sua produção Ihe dará visibilidade em meio a tantos outros. Estendemos isso a todo o trabalho das editoras. Dessa maneira, ilustradores e autores começam a dividir o mérito pela alta qualidade de algumas produções, e tal qualidade garante-lhes o destaque em meio a tantos outros (CADEMARTORI, 2008). Ainda de acordo com a pesquisadora, alguns profissionais da área usam técnicas que aproximam sua arte das xilogravuras características da região nordeste do Brasil, outros das iluminuras e pinturas renascentistas. As cores escolhidas, por exemplo, estabelecem a relação entre ambientes e épocas, "cores metálicas são também dotadas de potencial evocativo ao sugerir efeitos cromáticos das armas forjadas usadas pelos cavaleiros, assim como dos adornos e indumentárias usadas no cangaço" (CADEMARTORI, 2008, p. 83).

A escrita apresenta uma configuração linear, já as ilustrações, em razão da riqueza de traços e cores, não apresentam tal linearidade, são capazes de cativar e comunicar ao mesmo tempo. Além disso, facilitam o acesso à narrativa pelos leitores, em especial crianças e jovens, visto que se configuram por, em certa medida, simbolizarem o real, proporcionarem esclarecimento quanto à história e permitirem que o indivíduo pense analiticamente sobre o tema e, assim, perceba as significações inscritas na história e pro- 
duza novas com base em seu arcabouço. As imagens deixam vazios e ambiguidades para que o próprio leitor os resolva, ampliando as possibilidades de sentidos (CADEMARTORI, 2008). Podemos inferir, pois, que se uma ilustração ou qualquer outro paratexto busca preencher todas as lacunas deixadas pelo texto escrito, as oportunidades de construção de sentidos por parte do leitor são absolutamente reduzidas, oferecendo-Ihe uma leitura carregada de significados construídos por outrem, restringindo sua experiência de leitura e ampliação da bagagem cultural.

O traçado das imagens, simples ou detalhado, também tem seu papel de influência nessa construção. Suas características variam segundo a intenção do autor, e quando sua expressividade é exagerada, tornam-se artificiais (RAMOS, 2011). Os traços são figurativos ou abstratos - os primeiros são reconhecíveis no mundo, os segundos, distanciam-se da realidade. Ramos (2011) afirma que as cores também refletem sensações e estados de espírito as quentes carregam entusiasmo, nervoso, emoções intensas; as frias, tranquilidade, calma.

\section{Análise: a escolha das obras}

Com a discussão anterior em mente, iniciamos nossa análise pelo conto machadiano intitulado Conto de escola, publicado no ano de 2002 pela editora Cosac Naify. O conto em questão foi escrito por Machado de Assis em 1884 e faz parte do volume Várias histórias (1896). A crítica machadiana central diz respeito à corrupção e à delação, presentes desde o universo infantil, corrompendo o ser humano já na infância. A editora Cosac Naify foi fundada no ano de 1997, mas encerrou seu trabalho quase 20 anos depois de inúmeros lançamentos. A ficha técnica do livro cataloga-o como literatura infantil e juvenil brasileira, mas, embora essa catalogação não seja suficiente para que seja consumida por esse público, é um grande indicativo das intenções da editora. Junto a isso, os paratextos visam adequá-la ao público pretendido (CHARTIER, 1994). 
Trata-se de uma edição em formato álbum, com aproximados 30 centímetros de altura, capa dura, que concede aspecto luxuoso ao livro e apresenta características recorrentes em livros infantis e juvenis. Impresso em papel couché, capaz de refletir mais a luz e conferir mais claridade às ilustrações e preservação de suas cores - não é um papel muito indicado para textos longos, pois cansa a vista com mais rapidez - o livro tem, no decorrer de suas 32 páginas, incluindo os paratextos (glossário e informações sobre o trabalho feito pelo ilustrador), 28 ilustrações, tratando-se, portanto, de uma obra rica em imagens. No entanto não é a quantidade de imagens que o torna uma obra com qualidade estética, mas sim o papel que elas desempenham na história (RAMOS, 2011).

Nelson Cruz foi o responsável pela ilustração e pelo projeto editorial da edição de "Conto de escola" (2002). De origem mineira, o autor e ilustrador nos informa, em seu blog pessoal , que ilustra para o mercado editorial desde 1998. Em um dos paratextos da edição, Cruz comenta que as imagens dessa obra foram "criadas por ocasião da edição chinesa de Conto de escola pela Editora Grimmpress, de Taiwan, no ano de 1998" (CRUZ, 2002, $s / n)$. Considera as ilustrações universais, e uma grande aventura poder se comunicar por meio delas. $\mathrm{O}$ artista procurou se basear em pinturas do século XVIII e XIX, em cenários do próprio Rio de Janeiro - época e ambiente em que se passa a narrativa. São feitas a partir de técnicas de pintura, o que valoriza a qualidade estética da obra, todas elas em tonalidade sépia. Ao proporcionar ao leitor o contato com expressões artísticas que aludem a pinturas, essa edição atende à função de levá-lo a uma educação estética (RAMOS, A., 2011).

A mancha textual pequena em cada página, com uma tipografia confortável para a leitura - tanto no que concerne ao tipo como ao tamanho da fonte -, dá ao leitor a impressão de que não há muito texto para ser lido, caracterizando, também, o design gráfico como atraente. A distribuição do texto pelas páginas permite ao leitor fechar as ideias para dar sequência à leitura, pois como considera Chartier (1999), parágrafos muito longos podem não 
cooperar para que o leitor assimile uma ideia para dar continuidade a sua leitura e, assim, compreender os sentidos propostos pelo texto e construir novos. Algumas páginas possuem pequenas imagens relacionadas à narrativa, as quais são localizadas tanto na parte superior como na parte inferior das páginas. Tais ilustrações têm por função auxiliar o leitor a compreender o universo da ficção (NIKOLAJEVA; SCOTT, 2011).

São ilustrações cujos traços fortes carregam muita tensão e suspense, graças às expressões faciais de medo dos alunos e de raiva do mestre ao ver os garotos conversando em momento indevido e trocando dinheiro por auxílio com a lição, por exemplo. Além disso, a dimensão e a proporção de uma personagem em relação à outra também apresentam essa ideia - o professor visivelmente maior que os dois garotos fortalece a imagem de opressão; nesse momento o leitor atento certamente se dará conta que um castigo severo está por vir. A predominância das cores quentes leva o leitor a se envolver em um movimento enérgico, como considera Graça Ramos (2011), ao afirmar que esses tons marcam sensações de entusiasmo e conflito. Em alguns momentos em que a narrativa se mostra mais tensionada, é possível perceber uma predominância do vermelho fechado na ilustração, envolvendo o leitor. Alguns traços semânticos não propostos pelo autor são, assim, colocados pelo ilustrador, instaurando-se uma vertente que perpassa pelo medo - mas não um terror, e sim um medo relacionado a sérias consequências e à severidade (FIGURAS 1 e 2). 
Figura 1 - Ilustração Conto de escola. Edição de Cosac Naify.
Figura 2 - llustração Conto de escola. Edição de Cosac Naify.

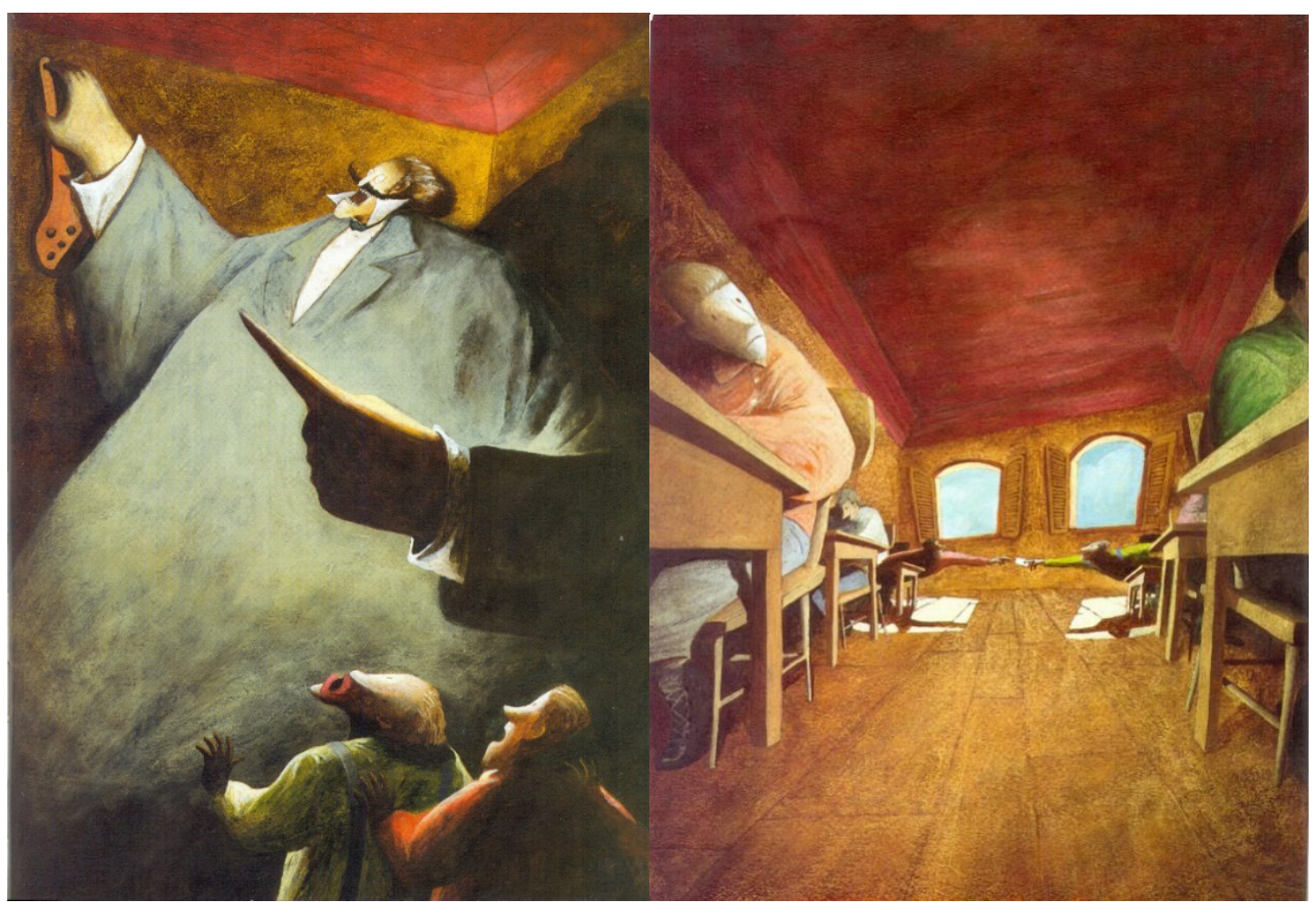

Fonte: ASSIS (2002, p. 18).

Fonte: ASSIS (2002, p. 23.)

Além das ilustrações, essa edição não possui muitos paratextos que aproximam o jovem e a criança do texto. Não existem contextualizações acerca de quem foi Machado de Assis, apenas uma menção encontrada na contracapa do livro, tratando-se de um brevíssimo resumo em cinco linhas sobre sua vida e obra. Logo abaixo, há informações relativas ao ano em que o conto foi escrito (1884) e de qual volume faz parte (Várias Histórias, 1896). Visto que não existem alterações textuais nesse conto, ao final encontramos um glossário, permitindo a aproximação do leitor ao universo do texto, contendo definições de palavras, como "sueto", e explicações de termos, como "Regência". Segundo Martha (2010), o glossário pode ser um recurso de aproximação entre leitor e texto, dessa maneira mais um recurso gráfico-editorial que deve ser levado em consideração na escolha de uma obra. O grande investimento na materialidade da edição possibilita uma educação estética, o con- 
tato com outras expressões artísticas, com uma obra que amplie seu conhecimento e leve-o a desenvolver sua sensibilidade e criticidade em relação a diferentes manifestações artísticas e culturais, o que desenvolveria a capacidade do leitor de atribuir significações e fazer inferências que vão além do texto escrito. Diana Maria Ferreira Martins e Sara Reis da Silva também apontam a importância da "materialidade e da aparência externa do livro no processo de leitura e interpretação enquanto reflexo evocatório ou tentador (por vezes, até mesmo crítico) da obra como um todo, como uma unidade na qual se interliga sinergicamente uma pluralidade de códigos" (MARTINS E SILVA, 2020, p. 5). Ademais, possibilita o cruzamento de barreiras da ficção, destinando um texto inicialmente escrito ao público adulto para leitores infantis e juvenis.

O segundo livro analisado, A Agulha e a Linha: Um apólogo, foi publicado em 2008 pela editora Ao Livro Técnico, ilustrado por Vitor Costa, carioca com experiência na área de Design. Caracterizamos a vertente adotada no projeto gráfico-editorial como infantil, pois tem traçados expressivos, objetos antropomorfizados, carregados de cores vivas; o papel "couché", escolhido para a edição, confere mais clareza e visibilidade às imagens. Existem inúmeras informações presentes por todas as páginas dos livros e, além das imagens que ocupam a maior parte das páginas, há pequenas manchas gráficas, termos circulados em vermelho com indicações de significados (desempenhando a função de um glossário) e balões de pensamentos, semelhantes aos das histórias em quadrinho, dando a entender que se tratam de reflexões acerca do narrado: informações e ideias com linguagem diferente da machadiana, simples e atuais. O último balão de pensamento, localizado na última página do livro, acompanha um homem posicionado de costas lendo/escrevendo o livro A Agulha e a Linha: Um apólogo, ou seja, como se houvesse um reposicionamento do ponto de vista, que sai do livro e enxerga quem o lê. Junto desse personagem há um balão de pensamento contendo a moral da história, o que pode significar que todos os balões no decorrer do livro pertencem a esse mesmo homem. (FIGURAS 3 e 4). 
Reembalagem: projeto gráfico e educação estética

Juliana Garcia de Mendonça Hanke • Alice Áurea Penteado Martha

Figura 3 - Ilustração A Agulha e a Linha: Um apólogo. Edição de Ao Livro Técnico.

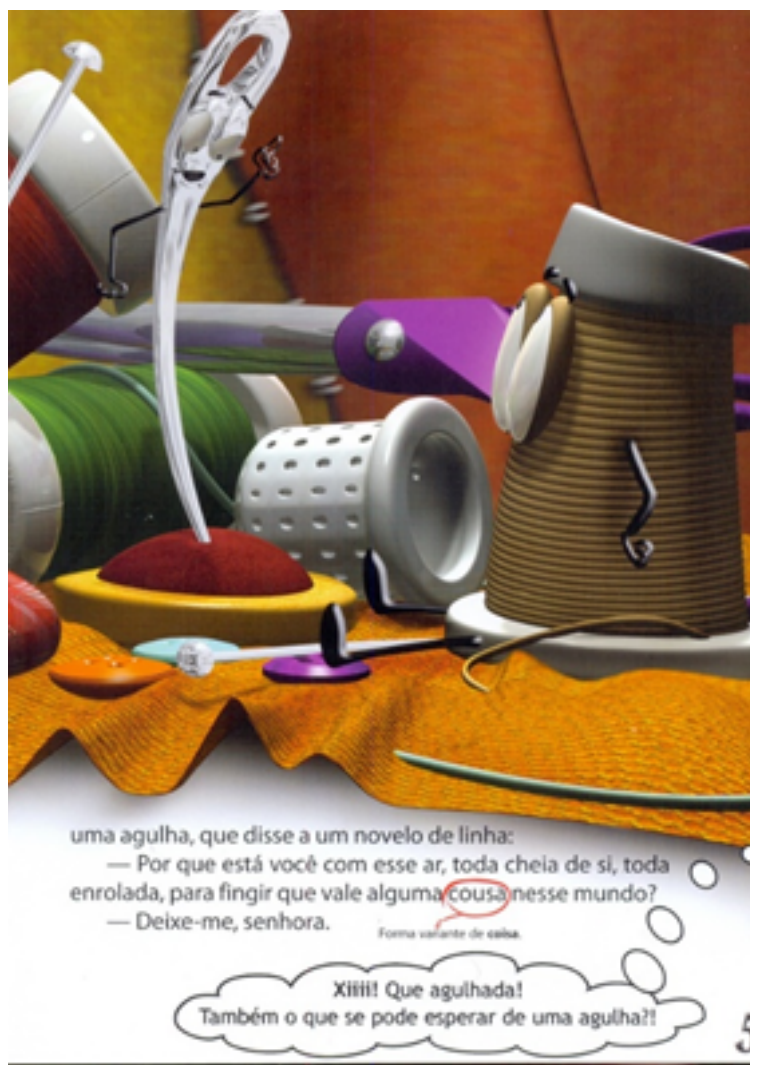

Fonte: ASSIS, (2008, p. 5)
Figura 4 - Ilustração A Agulha e a Linha: Um apólogo. Edição de Ao Livro Técnico.

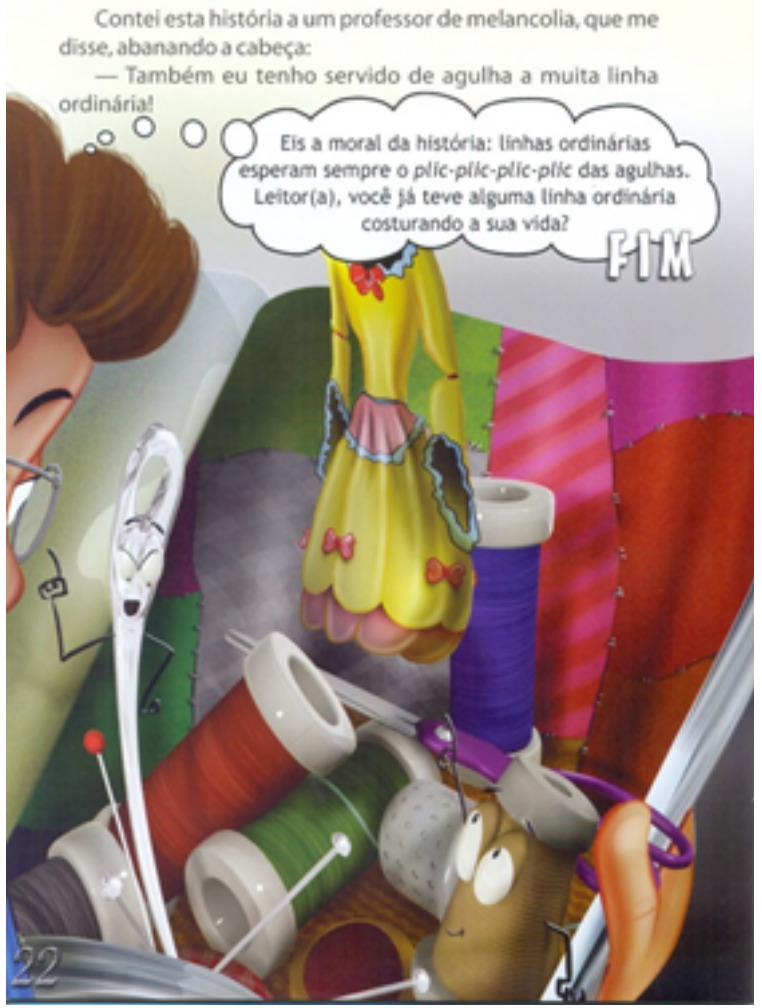

Fonte: ASSIS, $(2008$, p. 22)

A moral, que não acompanha o texto original de Machado de Assis, foi acrescentada nessa edição por um comentarista no processo de editoração, tratando-se de uma conclusão subjetiva e pessoal, mas não necessariamente a pretendida pelo escritor ou a construída pelo leitor em seu processo de leitura: “Eis a moral da história: linhas ordinárias esperam sempre o plic-plic-plic-plic das agulhas. Leitor(a), você já teve alguma linha ordinária costurando sua vida?" (GUERRA, 2008, p. 22). O questionamento é uma tentativa de promover reflexão e, ainda, de preencher as lacunas deixadas pelo narrador.

Nas primeiras páginas da obra, encontramos um texto intitulado "Alguns retalhos de mim". Trata-se de uma página muito co- 
lorida, repleta de desenhos de retalhos, na intenção de ser mais atrativa ao público infantil. Suas palavras pretendem mostrar que Machado de Assis, mesmo depois de morto, escreve para seus leitores. Uma breve bibliografia do escritor é narrada e a liberdade que o editor tem de "imitar a voz" de Machado é tão significativa que ele arrisca um apelido, "[o] afeto dos familiares e dos amigos deve ter me chamado de Quinzinho e Quincas. Não sei. A memória de um morto não é confiável" (GUERRA, 2008, p.03). Além disso, há uma explicação sumária acerca do gênero apólogo; um comentário a respeito do que há nas entrelinhas introduz a história narrada; por fim, um pedido ao leitor para que não acredite no que afirmam sobre ele ser um autor pouco acessível, convidando-o a ler o apólogo e se divertir.

Logo no verso da capa, encontramos a ficha catalográfica indicando o conto como "literatura infanto-juvenil" e, abaixo, dois pequenos parágrafos, contendo informações acerca de Machado de Assis e de Alberto Guerra (responsável pela editoração do livro), destinadas ao adulto responsável por comprar o livro, com linguagem mais distante do universo infantil e juvenil. O trecho designado ao escritor procura legitimá-lo como um autor renomado: "Machado de Assis (1839-1908). Principal matriz da mais alta arte brasileira, Joaquim Maria emprestou seu brilho a vários gêneros da criação [...]" (GUERRA, 2008, s/n).

As expressões características dos livros infantis, tanto a que inicia as narrativas, "ERA UMA VEZ", como a que as finaliza, "FIM", estão presentes nessa edição do conto machadiano, mais uma vez revelando a intenção do editor de cruzar os limites entre públicos. Ao prosseguirmos, encontramos o poema As Armas, de Fagundes Varela; no texto, assim como no conto, existem marcações em vermelho, acompanhadas de desenhos que ilustram as armas mencionadas. Não há nenhum comentário quanto ao propósito do poema de ter sido inserido no livro. A relação que conseguimos estabelecer refere-se à mais tremenda das armas - a língua - apresentada pelo poema e usada durante o desenvolvimento do enredo, tanto pela agulha como pela linha. 
Ao final da edição, um paratexto intitulado "A costura das cenas" mostra o processo de elaboração das imagens, com técnicas de desenho em terceira dimensão. Mas há apenas as cenas, sem explicações ou informativos. Em seguida, na contracapa encontramos a seguinte pergunta: "O que se pode fazer com uma agulha e um novelo de linha?", e imediatamente é dada a resposta, "Costurar, é claro". A questão e a resposta são seguidas por uma breve reflexão que correlaciona a costura à vivência e ao arrependimento das pessoas.

A terceira obra, Uns braços, edição de 2012, lançada pela editora SESI-SP e ilustrada por Fernando Vilela, é um conto escrito em 1885. Em um dos paratextos do livro é revelada a preocupação do ilustrador quanto ao trabalho de alta qualidade, para o qual realiza uma pesquisa iconográfica, com vistas a melhor conhecer os objetos, os costumes, as personagens e os locais da época da narrativa. Informa que, por se tratarem de contos escritos há mais de 100 anos, buscou a aparência de livro envelhecido com as folhas infestadas por fungos; para tal efeito, revela ter elaborado esse fundo com base nas páginas de um livro de 1890. A editoração da obra optou por fontes tipográficas originadas nesse século com características dessa época, a saber, Old Style 7, usada no corpo do texto. Essas escolhas, aliadas à predominância da cor ocre e da tonalidade sépia, transportam o leitor para um tempo mais antigo.

Folhas brancas estão presentes apenas ao final do livro para dar suporte aos paratextos finais: um glossário, com vistas a aproximar o texto do universo do leitor (MARTHA, 2010); um pequeno trecho sobre a vida de Machado de Assis, para fazê-lo conhecido e diminuir a distância entre leitor e texto; um parágrafo que explica a intenção da publicação de trazer visibilidade às narrativas de Machado, levando o público a conhecer o ambiente do século XIX, bem como a cultura, por meio das ilustrações; um texto explicando o trabalho de elaboração do projeto-gráfico e das imagens, feitas com base na realidade da época em que o conto é ambientado, bem como algumas fotos dessa época. 
O papel offset $120 \mathrm{~g} / \mathrm{m} 2$ oferece qualidade às imagens e conforto para a leitura do texto escrito, pois um papel couché, por exemplo, destoaria da proposta de apresentação de um livro com aspecto envelhecido. Os pequenos detalhes escolhidos nessa edição - tipo do papel, tamanho e formato da fonte, mancha gráfica, ilustração, diagramação, paratextos - podem passar despercebidos pelo público, o qual, em geral, não nota sua influência no momento da leitura (MARTHA, 2010), todavia cada um deles é importante para a composição do livro e para levar o receptor a um mergulho nos anos de 1800. As ilustrações seguem estilo e técnica que misturam xilogravura e traçados rascunhados, oferecendo ao leitor contato com uma manifestação artística diferente e a possibilidade de uma educação estética (FIGURA 5). A variedade de cores é recorrente no fundo das páginas, são cores equilibradas que variam das frias para as quentes de acordo com o conteúdo da narrativa.

O enredo revela a agitação e a confusão dos sentimentos de $D$. Severina, uma mulher casada, e Inácio, um garoto de 15 anos que está hospedado em sua casa. De fato, é um conto aparentemente mais romântico, em que D. Severina e Inácio se encantam um pelo outro, todavia, lembremos que se trata de um conto da fase madura de Machado, portanto o romantismo é subjugado pela realidade. Destacamos, pois, o trabalho gráfico-editorial concordante com o texto machadiano: suas ilustrações coloridas, com cores em equilíbrio para acompanhar um conto que não possui um clima pesado. Mencionamos o auge do conto grafado em letras brancas em fundo preto - único momento em que o editor lançou mão dessa cor para o fundo. Nesse caso, essa opção vem identificar a ousadia do ocorrido, quando D. Severina permite que seus desejos falem mais alto que sua razão e, enquanto Inácio dorme em sua rede, a mulher "[...] inclinava-se, pegava-Ihe outra vez das mãos e cruzava ao peito os braços, até que, inclinando-se, ainda mais, muito mais, abrochou os lábios e deixou-lhe um beijo na boca" (FIGURA 6). O rapaz fica sem saber se o beijo fora sonho ou realidade. Juntamente com os outros elementos gráficos, as ilustrações 
contribuem para a adequada ambientação e imersão do leitor no conto, oportunizando construção de novos sentidos para o texto, que pode ser caracterizado como uma obra de vertente histórica.

Figura 5 - Ilustração Uns braços.

Edição de SESI-SP editora.

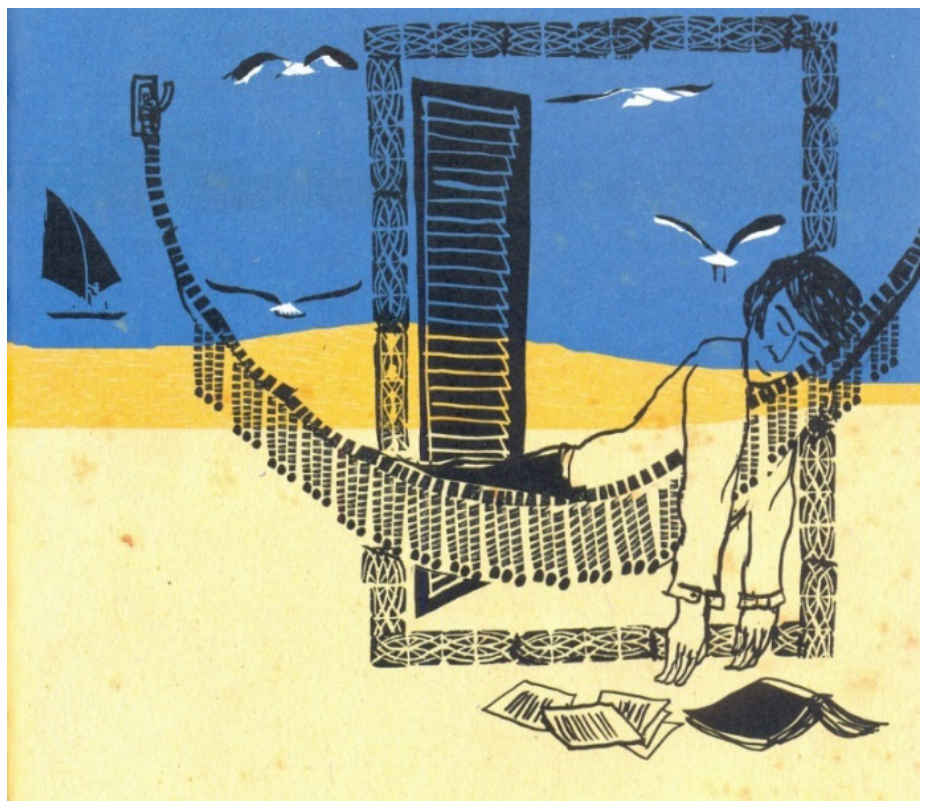

Fonte: Assis (2017, p. 23).
Figura 6 - Ilustração Uns braços. Edição de SESI-SP editora.

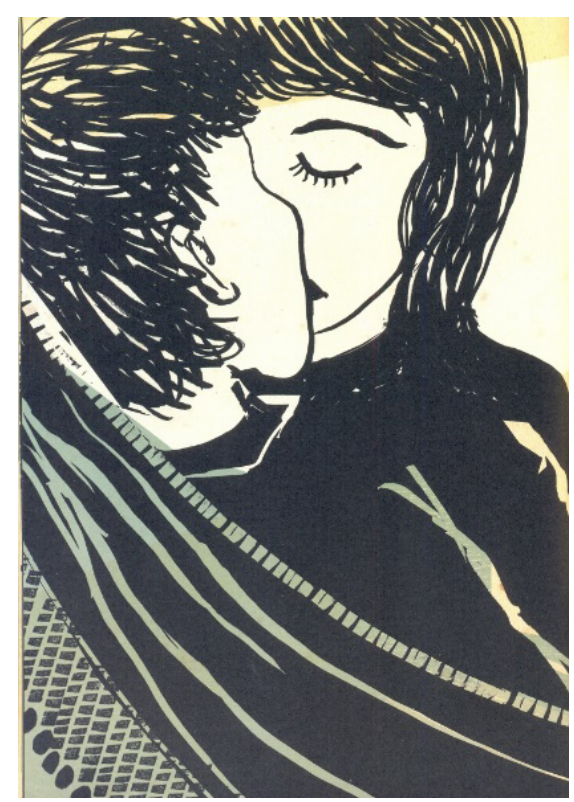

Fonte: Assis (2017, p. 30).

Diante dos três livros analisados, levantamos três vertentes diferentes em obras machadianas, cujo texto permanece na íntegra, mas o trabalho do mercado editorial possibilita o crossover, levando essas narrativas a circularem entre o público infantil e juvenil. Essas vertentes são voltadas à tensão, à infantilização e a características históricas. Todas as questões levantadas permitem verificarmos que estamos diante de opções diversas de livros publicados por diferentes editoras, as quais proporcionam em maior ou menor grau a educação estética do leitor. Como o projeto gráfico-editorial orienta em grande medida a leitura do público, faz-se necessária a consciência diante da escolha da obra de uma editora ou de outra. O investimento material pode proporcionar o reendereçamento de um texto, mas, ao mesmo tempo, pode conferir a ele valor estético ou perda de seu valor intrínseco como um bem simbólico (BECKETT, 2009, p. 180). 


\section{Considerações finais}

Ao longo deste artigo, verificamos que o mercado do livro, orientado pelo fenômeno crossover fiction (BECKETT, 2009), realiza um intenso trabalho de reendereçamento de contos machadianos, os quais, inicialmente escritos para adultos, e para um público de outro tempo, chegam às mãos de crianças e jovens, mais de cem anos depois. Deliberadamente, as editoras vendem as criações do escritor oitocentista como livros infantis e juvenis, operando apenas alterações materiais. A partir da análise de três contos publicados por três editoras distintas, conferimos que tal trabalho pode, em certa medida, oferecer uma educação estética ao leitor. As análises de características gráficas escolhidas pelos editores apontaram para o trabalho editorial que diminui a distância entre texto e público. Alguns trabalhos, na intenção de reduzir tal distância, acabam por dificultar as possibilidades de leitura e as construções de sentidos (BECKETT, 2009).

Essas considerações pretendem contribuir para o desenvolvimento de pesquisas acerca da literatura infantil e juvenil sob a perspectiva do investimento material feito pelo mercado livreiro. Tendo em vista que o fenômeno de cruzamento das fronteiras da ficção ainda é um campo que merece atenção, buscamos despertar o interesse de pesquisadores e estudantes da área para a compreensão da existência de um investimento cada vez maior e mais explorado pela indústria do livro e para a importância que tal movimento tem por viabilizar que um texto se torne acessível a diferentes públicos. Como são muitas as editoras que lançam e relançam os textos machadianos, é necessário, ao optarmos por uma edição, levar em consideração a oferta de uma educação estética e as possibilidades de construção de sentidos.

Existe uma série de fatores que precisam ser considerados para que a relação estabelecida entre o leitor e a obra não torne a leitura uma experiência vazia de sentido e propósito, gerando apenas a aversão pelos clássicos da literatura, vistos como muito 
"difíceis", ou ainda apenas aumentando o número de leitores no nosso país, mas reduzindo cada vez mais os leitores que são habilitados para ler e interpretar.

\section{Referências}

ALMEIDA, C. S. de. Reformas de um projeto gráfico: uma análise da coleção do Sítio do Picapau Amarelo em três tempos. 2015. 191 f. (Dissertação Mestrado em Comunicação Social) - Universidade do Estado do Rio de Janeiro, Rio de Janeiro. 2015.

ASSIS, M. de. A agulha e a linha: Um apólogo. Projeto editorial, organização e comentários Alberto Guerra. 2. ed. Rio de Janeiro: Ao Livro Técnico, 2008.

ASSIS, M. de.. Uns braços. Ilustração Fernando Vilela. São Paulo: SESISP, 2017.

ASSIS, M. de.. Conto de escola. Ilustração e projeto editorial Nelson Cruz. São Paulo: Cosac Naify, 2002.

BECKETT, S. Crossover fiction: global and historical perspectives. New York: Routledge, 2009.

BOURDIEU, P. A economia das trocas simbólicas. Introdução, organização e seleção Sergio Miceli. Tradução Sergio Miceli, Silvia de Almeida Prado, Sonia Miceli e Wilson Campos Vieira. 8. ed. São Paulo: Perspectiva, 2015.

CADEMARTORI, L. Para não aborrecer Alice: A ilustração no livro infantil. In: PAIVA, A.; SOARES, M. (Org.). Literatura Infantil: políticas e concepções. Belo Horizonte: Autêntica Editora, 2008. p. 79-90.

CHARTIER, R. N. A ordem dos livros: leitores, autores e bibliotecas na Europa entre os séculos XIV e XVIII. Tradução Mary Del Priori. Brasília: Editora Universidade de Brasília, 1999. 1. ed., 1994.

ECO, U. Apocalípticos e integrados. Tradução Pérola de Carvalho. 1. reimpr. da 7. ed., 2011. São Paulo: Perspectiva, 2015. 
GUERRA, A. Alguns retalhos de mim. In: A agulha e a linha: Um apólogo. 2. ed. Rio de Janeiro: Ao Livro Técnico, 2008

GUIMARÃES, H. de S. Os leitores de Machado de Assis: O romance machadiano e o público de literatura no século 19. 15 de janeiro de 2001. 438 f. Tese (Doutorado). Universidade Estadual de Campinas, Instituto de Estudos da Linguagem, 2001.

MARTHA, A. A. P. Mercado editorial e efeméride: Machado de Assis para jovens leitores. In: CIELLA - CONGRESSO INTERNACIONAL DE ESTUDOSLINGUÍSITCOS E LITERÁRIOS NA AMAZÔNIA, 2, 2009, Belém. Anais... Belém: UFPA, vol. 1, 2010. p.67-75.

MARTINS, D. M. F., \& SILVA, S. R. da. (2020). Algumas notas sobre os livros infantis na hipermodernidade: O Polegarzinho ou As Botas de Sete Léguas numa seleção de livros-objeto para a infância. Acta Scientiarum. Language and Culture, 42(2), e54198. https://doi. org/10.4025/actascilangcult.v42i2.54198, 2020.

NIKOLAJEVA, M.; SCOTT, C. Livro ilustrado: Palavras e Imagens. Tradução Cid Knipel. São Paulo: Cosac Naify, 2011.

RAMOS, A. M. Apontamentos para uma poética do álbum contemporâneo. In: O álbum na literatura infantil e xuvenil (2000-2010). RECHOU, B. R.; LÓPEZ, I. S.; RODRÍGUEZ, M. N. (Org.). Vigo: Edicións Xerais de Galicia, S.A., 2011. p. 13-40.

RAMOS, G. A imagem nos livros infantis: Caminhos para ler o texto visual. Belo Horizonte: Autêntica Editora, 2011. 